UCRL-ID-108882

\title{
Nondestructive and Quantitative Characterization of TRU and LLW Mixed-Waste Using Active and Passive Gamma-Ray Spectrometry and Computed Tomography
}

TTP No. SF-9200-11

David C. Camp

Harry E. Martz

This Technical Status Report was Prepared in

Response to INEL's

Buried Waste Integrated Demonstration

November 12, 1991

This is an informal report intended primarily for internal or limited external distribution. The opinions and conclusions stated are those of the author and may or may not be those of the Laboratory.

Work performed under the auspices of the U.S. Department of Energy by the Lawrence Livermore National Laboratory under Contract W-7405-Eng-48. 


\section{DISCLAIMER}

This document was prepared as an acccount of work sponsored by an agency of the United States Government. Neither the United States Government nor the University of California nor any of their emplovees, makes any warranty, express or implied, or assumes any legal liability or responsibility for the accuracy, completeness, or usefulness of any information, apparatus, product, or process disclosed, or represents that its use would not infringe privately own rights. Reference herein to any specific commercial products, process, or service by trade name, trademark, manufacturer, or otherwise, does not necessarily constitute or imply its endorsement, recommendation, or favoring by the United States Government or the University of California. The views and opinions of authors expressed herein do not necessarily state or reflect those of the United States Government or the University of California, and shall not be used tor advertising or product endorsement purposes.

This report has been reproduced directly from the best available copy.

Available to DOE and DOE contractors from the Office of Scientific and Technical Information

P.O. Box 62, Oak Ridge, TN 37831

Prices available from (615) 576-8401, FTS 626-840

Available to the public from the National Technical Information Service

U.S. Department of Commerce 5285 Port Royal Rd. Springfield, VA 22161 
UCRL-ID--108882

DE92 003888

\author{
BURIED WASTE INTEGRATED DEMONSTRATION \\ TECHNOLOGY STATUS REPORT \\ FOR
}

Nondestructive and Quantitative Characterization

of TRU and LLW Mixed-Waste Using

Active and Passive Gamma-Ray Spectrometry

\title{
and Computed Tomography
}

TTP No. SF-9200-11

\author{
by \\ David C. Camp \\ and Harry E. Martz
}

November 12, 1991

Prepared by

Lawrence Livermore National Laboratory

Livermore, California 94550

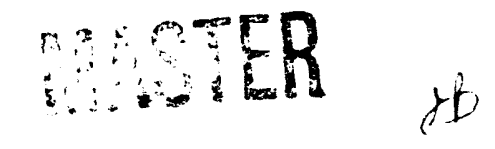




\section{Nondestructive and Quantitative Characterization \\ of TRU and LLW Mixed-Waste Using Active and Passive Gamma-Ray Spectrometry and Computed Tomography}

\section{TABLE OF CONTENTS}

Page No.

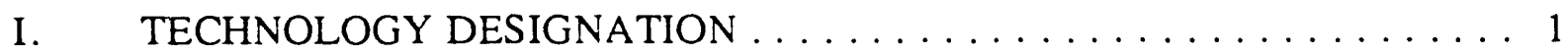

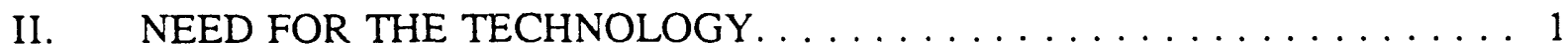

III. DESCRIPTION AND EVALUATION OF TECHNOL $\cap G Y \ldots \ldots \ldots \ldots \ldots . . .3$

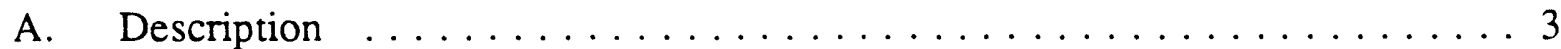

B. Demonstrated Performance ......................4

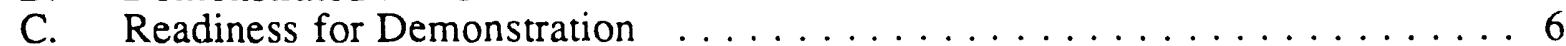

D. Projected Performance vs Baseline Technolgy .................6

E. Regulatory Requirements and Public Acceptance. . . . . . . . . . . . 7

IV. DEMONSTRATION REQUIREMENTS $\ldots \ldots \ldots \ldots \ldots \ldots \ldots \ldots$

A. Data Requirements $\ldots \ldots \ldots \ldots \ldots \ldots \ldots \ldots \ldots \ldots$

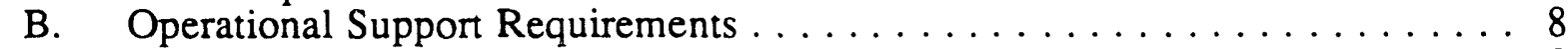

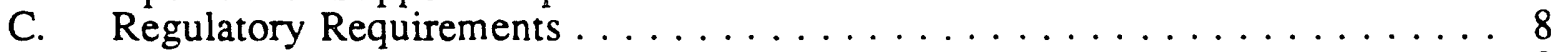

D. Schedule Requirements $\ldots \ldots \ldots \ldots \ldots \ldots \ldots \ldots \ldots \ldots \ldots \ldots$

E. Funding Requirements $\ldots \ldots \ldots \ldots \ldots \ldots \ldots \ldots \ldots$

V. CONCLUSIONS AND RECOMMENDATIONS .............. 10

\section{FIGURES}

Fig. 1. Number of Drums Stored and Buried at Some DOE Sites . . . . . . . . . 2

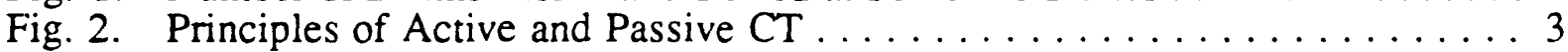

Fig. 3. Conceptual Sketch for a 5-HPGe-Detector A\&P CT Drum Scanner . . . . . . . 3

Fig. 4. Radiograph of a 1/6-th Scale 55-gallon Drum and two ACT Images ........ 4

Fig. 5. Radiograph, ACT and PCT Images of another $1 / 6$ th Scale 55 -gallon Drum . . . 5

Fig. 6. Spatial Attenuation Data Available from ACT Images . . . . . . . . . . . . . 5

Fig. 7. Bar Chart Schedule for Proposed 1-HPGe-Detector A\&P CT Demo Scanner . . 8

Fig. 8. Schedule for IMPACT, a 5-HPGe-Detector, Full-Scale Scanner System . . . . 9

TABLES

TABLE I. Projected Costs (k\$) for a 1-HPGe-Detector A\&P CT Scanner Demonstration . 9 


\section{Nondestructive and Quantitative Characterization of TRU and LLW Mixed-Wasti Using Active and Passive Gamma-Ray Spectrometry and Computed Tomography}

\section{TECHNOLOGY DESIGNATION}

The technology being proposed by LLNL is an Active and Passive Computed Tomography (A\&P CT) Drum Scanner for contact-handled $(\mathrm{CH})$ wastes. It combines the advantages offered by two well-developed nondestructive assay technologies: gamma-ray spectrometry and computed tomography $(\mathrm{CT})$. Coupled together, these two technologies offer to nondestructively and quantitatively characterize mixed-wastes forms.

Gamma-ray spectrometry uses one or more external radiation detectors to passively and nondestructively measure the energy spectrum emitted from a closed container. From the resulting spectrum one can identify most radioactivities detected, be they transuranic isotopes, mixed-fission products, activation products or environmental radioactivities. Spectral libraries exist at LLNL for all four.

Active (A) or transmission CT is a well-developed, nondestructive medical and industrial technique that uses an external-radiation beam to map regions of varying attenuation within a container. Passive $(P)$ or emission CT is a technique mainly developed for medical applications, e.g., single-photon emission CT. Nondestructive industrial uses of PCT are under devclopment and just coming into use. PCT allows one to localize and identify most of the detected radioactivities within a closed container. The fundamental key is to use the ACT attenuation data to correct the PCT data for either homogeneous- or heterogeneouswaste-matrix absorption. The result is an accurate, quantitative assay of all detectable radioisotopes within a waste form.

\section{NEED FOR THE TECHNOLOGY}

The environmental and operational problem being addressed is the characterization and classification of various nuclear waste forms. Some of these wastes are buried, while non-buried waste forms exist in various sized boxes, drums, crates and specialized containers. All of these waste forms are subject to numerous disposal and shipment regulations, which are increasing both in number and in specificity.

There are numerous regulations relevant to the categorization of nuclear wastes. Three important statues are 40 CFR 191, which discusses environmental radiation protection standards for the disposal of TRU wastes; 10 CFR 61 discusses the licensing requirements for land disposal of radioactive wastes; and 40 CFR 264 defines site performance and RCRA [Resource Conservation and Recovery Act] requirements. Other DOE regulatory requirements are specified in DOE 5820.2A. It discusses regulations relevant to all classes of radioactive wastes. DOE 069 Rev 4 discusses the Waste Isolation Pilot Plant (WIPP) waste acceptance criteria for both contact- $(\mathrm{CH})$ and remote-handled $(\mathrm{RH})$ wastes and mixed TRU wastes. Finally, 49 CFR 173 covers regulations applicable to the transportation of radioactive wastes. Other federal regulations require the identification of volatile and non-volatile organic compounds (VOCs and non-VOCs) and of hazardous heavy metals. More discussion of these regulations appears in Ref. [1].

Drummed, boxed, and crated wastes exist at almost every DOE site. Over one million nuclear waste drums are stored or buried throughout the DOE Complex [2] and current drum-generation rates exceed 10,000/year. Future DOE decontamination and decommissioning (D\&D) efforts will increase this rate dramatically [3]. All DOE wastes generated are assumed to be transuranic unless shown to be otherwise. Thus, all wastes must be certified as below regulatory concern, low level wastes (LLW), transuranic (TRU) or outside the bounds of the latter. Their accurate characterization will also assist in the safe handling, storage, and further treatment of their contents, if necessary. 
Many drums are located at those sites shown in Fig. 1; and these and all other DOE sites will eventually ship their TRU certified $\mathrm{CH}$ wastes to WIPP, while their certified LLW will be shipped to regional land disposal sites once established. All DOE sites will require sufficient nondestructive assay (NDA) or evaluation (NDE) assay instrumentation to certify that their wastes meet all relevant regulations. Hence, all DOE sites will benefit from the development and implementation of a noninvasive technology that identify the presence of VOCs, non-VOCs or heavy metals.

We will demonstrate a 55-gallon A\&PCT, CH waste-drum scanner. Once it is successfully demonstrated, the technology can be further developed to characterize drums with 30- to 96-gal. capacity and small boxes $\left(\sim 1^{\prime} \times 2^{\prime} \times 2^{\prime}\right)$. In the future, the technology may be developed to quantify the contents of larger sized containers such as crates $\left(4^{\prime} \times 4^{\prime} \times 7^{\prime}\right)$, remote-handled (RH) waste forms, and reactor fuel bundles.

The proposed A\&P CT drum scanner will be a system that will easily integrate into INEL's Buried Waste Characterization management plan [4]. It will consists of a computer-controlled, motorized, drumplatform that very accurately positions and repositions a drum horizontally, rotationally, and in elevation. The system will also include a transmission source $\left({ }^{166} \mathrm{Ho}\right)$; sufficient shielding to protect personnel from the transmission beam source and from any activity within the drum; one high-purity germanium (HPGe) radiation detector with supporting pulse electronics; a computer to process signals and data; a mass storage device to store spectra and data; an operator terminal; and an output printer. Small containers and drums would be inserted into the A\&P CT scanner system and, in effect, automatically scanned. Results would indicate whether the waste are: below LLW guidelines; satisfy LLW requirements; are TRU; or exceed the TRU guidelines. Results would also satisfy RCRA and Department of Transporation (DoT) regulations.

The proposed A\&P CT scanner will generate a complete description of the internal contents of a waste drum that existing techniques cannot provide. For NDA purposes the scanner will accurately identify, localize and quantify detected isotopes within the drum, and provide a 3-D attenuation map of drum contents. Currently, three NDE/NDA techniques are used: real-time radiography (RTR), segmented gamma-ray scanning (SGS) and passive-active neutron (PAN) interrogation. RTR is an NDE method that portrays $\mathrm{x}$-ray transmission images of a drum's contents on a TV screen so that nonconforming materials (e.g. free liquids, pressurized containers, etc.) are identified. SGS is an NDA method designed to measure only the amount of detectable ${ }^{235} \mathrm{U}$ or ${ }^{239} \mathrm{Pu}$ present in a waste drum and it does not localize any activity, nor does it properly correct for the absorption of any overlying matrix materials. PAN is an NDA method that determines the gram amount of spontaneous (passive) and induced (active) fissionable isotopes present in wastes. It does not properly correct for either absorption or neutron multiplication caused by the waste matrix materials. Both NDA techniques were developed to determine fissile materials in homogeneous waste forms and have been somewhat successful. However, they were not intended to be used to characterize all forms of wastes as current regulations require, and they do not obtain meaningful data for heterogeneous-waste forms [5]. Therefore, both are continuously being retrofitted and improved [6] to try to meet current regulations. Future regulations may become even more stringent and restrictive.

Due to the shortcomings of current NDA techniques, the quality of the A\&P CT data would best be determined by comparing scanner results to "working-reference-material drums" being fabricated by the Interface Working Group [5]. A\&P CT generates detailed attenuation and isotopic information per volume element (voxel $=\Delta x, \Delta y, \Delta z$ ) within a waste drum, information which is unattainable by RTR or SGS. A\&P CT data can be used to calculate both RTR and SGS results, since the former is just a 2-D projection of a 3-D drum and the latter provides data averaged over many voxels for a segment of the drum. Therefore, A\&P CT data sets car "interrogate" the accuracy of RTR, SGS, and PAN scans but not visa versa. Since the proposed A\&P CT data define the waste-matrix composition more accurately than either SGS or PAN, its results may modify their data and define how best to use the latter two techniques. The extent to which A\&P CT data can improve RTR or PAN results must await results from the A\&P CT scanner. 


\section{A. Description}

\section{Operating Principles}

The equipment and operating principle of the A\&P CT drum scanner is similar to that used for an SGS drum scanner, but differs in three respects. The CT scanner performs a complete spectral analysis, more elaborate drum manipulation, and image reconstruction. Figure 2 shows the two measurement modes required for active $(\mathrm{A})$ and passive $(\mathrm{P})$ computed tomography or CT. CT requires a container be translated, rotated and elevated through positional steps that are selectable in size. The main motion difference between the proposed A\&P CT and the SGS scanner is that the former uses well-collimated active and passive beam measurements. This collimation requires an additional degree of freedom, i.e., horizontal translation of the drum completely across the active beam. This is not required by the SGS scanner.

The ACT mode shown in Fig. 2 utilizes a well collimated gamma-ray source to interrogate the attenuation of wastes within a drum. Gamma-ray attenuation will decrease with increasing gamma-ray energy; while for any given energy, attenuation will decrease with increasing material density. The source strength is known but the attenuation function of the transmitted radiation is unknown. Recording data at multiple mono-energetic gamma ray energies simultaneously allows one to reconstruct a "map" of the $3-D$ distribution of internal materials. The PCT mode is carried out using similar translation, rotation, and elevation steps as used for ACT. The PCT mode measures all detectable radioactivities within a drum by using one or more collimated HPGe detectors outside the drum. PCT makes no assumptions about the contents of a drum or the strength of any internal radioactivities. In principle, it localizes all detectable radioactivities.

Coupling the ACT and PCT modes allows one to make accurate and quantitative attenuation corrections specific to the location of any radioactivity detected. Thus, one is able to identify and quantify accurately most detected isotopes within the drum. The results for the total drum activity and mass can be printed out in tabular form as a function of isotope, and both modes can be displayed as 3-D images.

\section{Full Scale Operations}

Figure 3 shows a conceptual drawing for a full scale, 5-HPGe detector, A\&P CT drum scanner. We call this system IMPACT: Isotope Measurement by Passive and Active Computed Tomography. A system with n-detectors will allow data to be taken in both the $A$ and $P$ CT modes about $n$-times faster than when a single detector is used. We believe practical measurements will show that the ACT and PCT measurements must be performed separately. The active mode uses a very strong source in order to provide high-quality attenuation "map" information as rapidly as possible, while the passive measurement seeks to localize and identify the weakest internal radiations detectable.

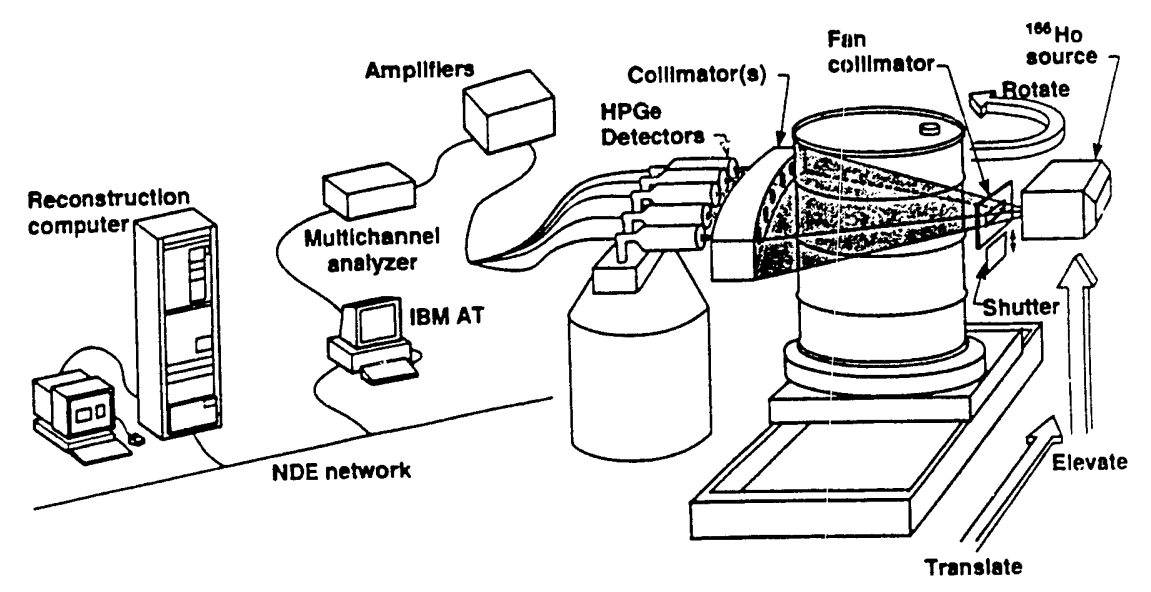

Fig. 3. Sketch of IMPACT, a 5-HPGe detector A\&P CT drum scanner. $-3-$ 
In addition, multiple mono-energy ACT maps can be used to determine the density and viffective atomic numbers as a function of spatial location. These may allow us to evaluate and localize both nonvolatile organic compound (non-VOC) materials and heavy metals. Coupling the ACT maps with the RTR image data may positively identify occasional unidentifiable drum contents. Finally, the spatial density and effective-atomic-number information obtained may improve PAN's neutron interrogation results, because the ACT results can be used to model, and thereby better define, the often unknown or poorly known heterogeneous matrix of materials within a drum.

Finally, in order to implement a full-scale A\&P CT system at the demonstration site (assumed to be INEL's Stored Waste Experimental Pilot Plant or SWEPP), careful coordination between the developers (LLNL) and implementers (INEL) must occur. However, SWEPP's flow sheet would not change since it routinely handles waste drums tur existing RTR, PAN and SGS systems. Drum throughput would depend on the time spent scanning a drum with a single- or multiple-HPGe-detector system. Such an A\&P CT scanner will have little to no impact on SWEPP's mass balance, its design, its operational or its maintenance requirements. Provision for resupply of liquid nitrogen (LN) for the scanner's HPGe detector(s) will be required. The full-scale drum scanner will produce no effluent nor any by-products.

\section{Relationship between Proposed Demonstration and Full-scale Operation}

We propose to demonstrate a 1-HPGe detector A\&P CT drum scanner. For this system only the center detector of the five shown in Fig. 3 is used, and the transmission-beam collimator will emit a "pencil" beam instead of a fan beam. Clearly, with fewer detectors, the time required to perform an entire drum scan will be longer than for a 5-HPGe-detector scanner.

The operational constraints on a proposed 1-HPGe-detector, demonstration system will be somewhat reduced from those required for a full-scale 5-HPGe-detector system. A 1-HPGe-detector A\&P CT drum scanner system will require less SWEPP-site preparation, but will probably require more handling of drums. The 5-HPGe-detector IMPACT system used in full-scale operations requires more development time, but once implemented would have an automated-drum-handling system; thus, requiring less "hands-on" interaction by SWEPP personnel.

\section{B . Research to Date: Demonstrated Performance}

LLNL has successfully developed $x$ - and gamma-ray ACT for the past 6 years [7-9] and PCT for the past year [10]. These efforts have been directed at obtaining high-spatial-resolutions on relatively small-sized objects $\left(\sim 1-\right.$ in. $^{3}$ to $\left.1-\mathrm{ft}^{3}\right)$. Therefore, in examining the use of A\&P CT for the nondestructive analysis of mixed-waste drums, we used existing, well-developed CT systems to look at $1 / 6$ th-scale 55gallon drums. Since the concept has been successfully demonstrated at this scale, there is very little risk in the implementation of a full-scale system. It simply requires an extension of principles already achieved in the small-scale A\&P CT systems, but with the experimental parameters and equipment properly scaled for full-sized drums.

In FY1990 [7,8], we made an ACT scan using a ${ }^{60} \mathrm{Co}$ source on a $1 / 6$ th-scale, 55 -gallon drum that contained a drill bit gauge, a broken screw-driver, a rolled-up plastic booty, a plastic marking pen (nonVOCs), glass and plastic test tubes, Cd and $\mathrm{Pb}$ samples, and a 5-mil-thick thorium foil (heavy metal). A false-color radiograph of the can is shown in Fig. 4. Two false color ACT attenuation"maps" are shown to the right; they were reconstructed using the $1.17-\mathrm{MeV}$ gamma-ray from ${ }^{60} \mathrm{Co}$ at two different slice-plane heights. This demonstrates the ability of ACT technology to identify a broad range of material matrix attenuations noninvasively, non-VOC materials and heavy metals. Note that the 5-mil-thick thorium foil translates into a 30-mil-thick piece of heavy metal within a full-sized 55-gallon drum. The ACT data can also be reconstructed and displayed in 3-D fashion for better visualization at any angle or perspective.

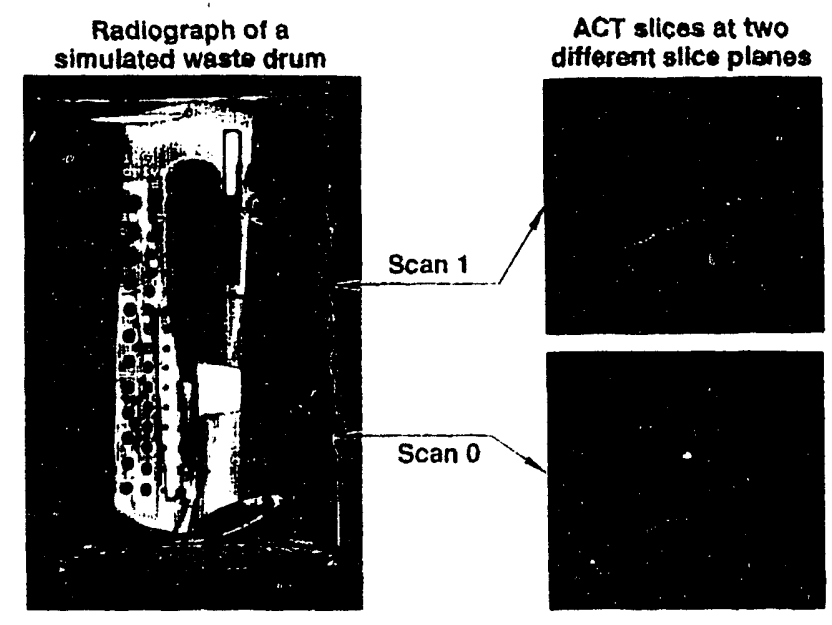

Fig. 4. Radiograph of a 1/6-scale 55-gallon waste drum. See text for content description. Reconstructed CT images of two slice planes from the $1.17-\mathrm{MeV}{ }^{60} \mathrm{Co}$ peak. 
In FY1991, we demonstrated [10] our PCT capabilities by localizing, identifying and quantifying a $95 \mu \mathrm{Ci}{ }^{133} \mathrm{Ba}$ radioisotope source that was located inside a 1/6th-scale, 55-gallon drum. Figure 5 shows a radiograph of the container, one ACT image and one PCT image. The ACT scan at 317 $\mathrm{keV}$ was acquired using an ${ }^{192} \mathrm{Ir}$ source and shows the location of blocks of lucite located at $\left(0^{\circ}\right)$, glass $\left(72^{\circ}\right)$, copper $\left(144^{\circ}\right)$, concrete $\left(216^{\circ}\right)$, aluminum $\left(288^{\circ}\right)$, and the location of a thin-mylar-covered metallic ring upon which the ${ }^{133} \mathrm{Ba}$ source was mounted. The PCT scan of the ${ }^{133} \mathrm{Ba}$ source at $303-\mathrm{keV}$ was acquired with the source surounded by the same collection of heterogeneous-matrix attenuators. The "bicycle-wheel-spoke-effect" in the PCT image reflects a limited number of emission

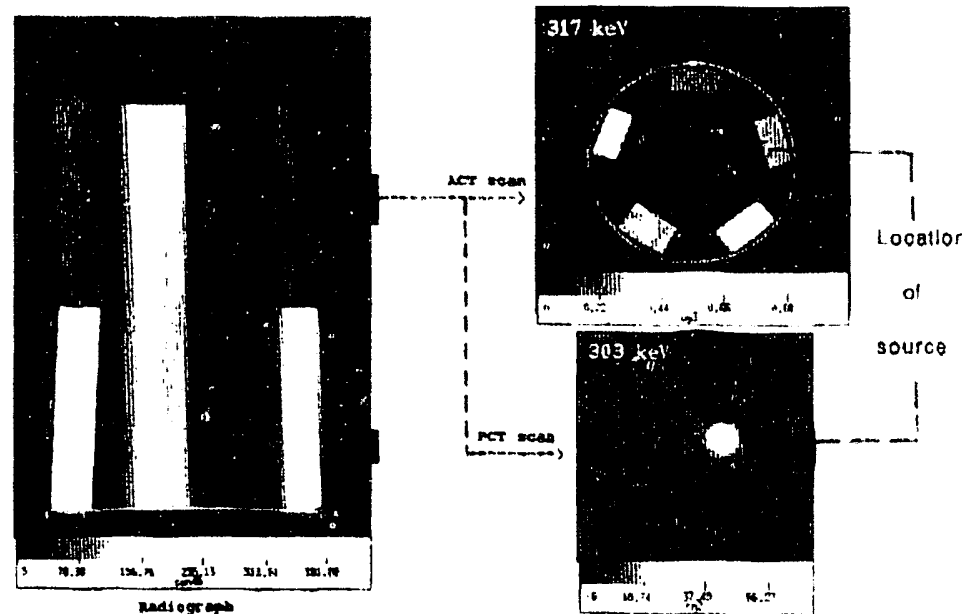

Fig. 5. Radiograph of a 1/6th-scale 55-gallon drum (left), and 317-keV ACT image (upper) and 303-keV PCT image (lower). projections, while the variation in spoke intensity indicates differing relative attenuations cause by the five different materials. The $317-\mathrm{keV}$ ACT attenuation data were used to accurately quantify the strength of the ${ }^{133} \mathrm{Ba}$-internal source at $303-\mathrm{keV}$ inspite of the heterogeneity of the materials within the can.

Knowing both the location of a radioisotope within a container and the attenuation of the overlying materials, we can apply near-exact attenuation corrections for any materials contained within a drum. The right hand part of Fig. 6 plots the linear attenuation coefficent versus distance along two selected paths in a $1 / 6$ th-scale 55-gallon drum. Such lineouts allow us to calculate accurate attenuation. corrections for all the activities that are detected. Adding up all of the contributions from all of the corrected radioactivities located within a drum results in a quantitatively accurate measurement of the total amount of internal radioactivity. Thus, we are able to declare the contents of

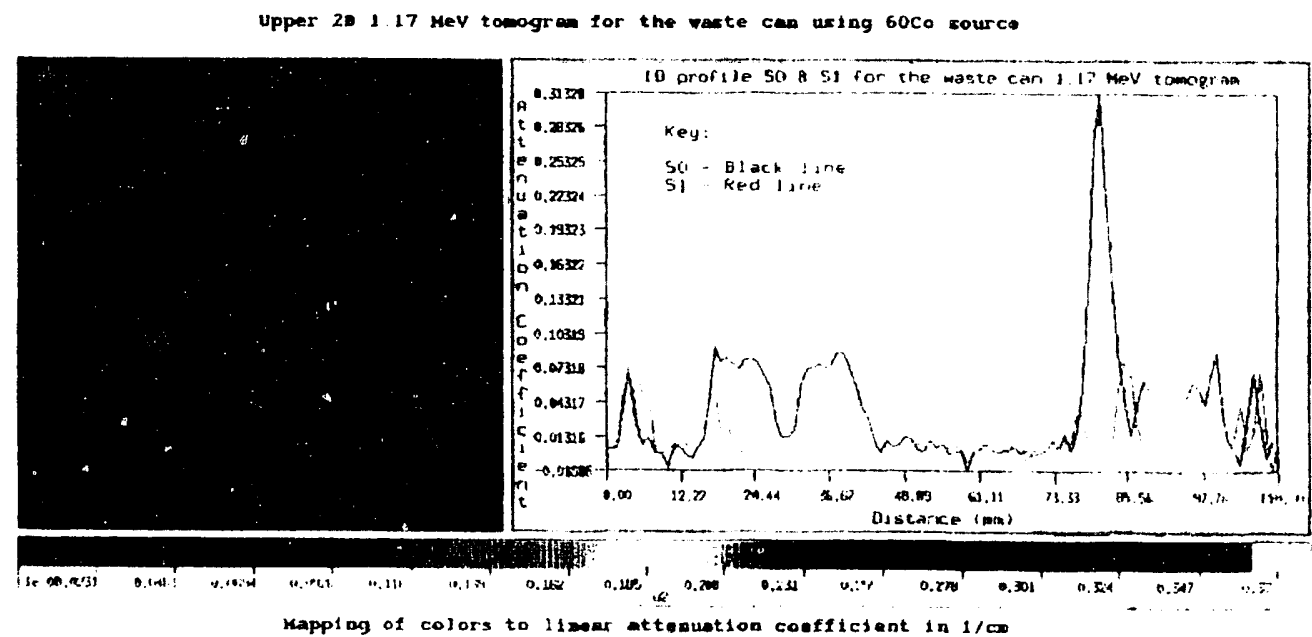

Fig. 6. The Scan 0 slice-plane map shown in Fig. 4 with two lineouts, SO and S1. The variation of linear attenuation across SO and S1 are shown to the right. Color-bar differences represent variations in the linear attenuation coefficients, which indicate variations in density and atomic number, i.e., air, screwdriver shaft, Th foil, glass, etc. mixed-wastes as low level (LLW), transuranic (TRU) or wastes outside the bounds of both categories.

For the proposed A\&P CT drum scanner, no significant "problem" areas remain but there are unresolved issues that must be clarified by means of a systematic development program. First, we must define the ACT and PCT operating parameters to be used in a 1-HPGe-detector-based system. This includes determining the optimum aperture for both the transmission source and HPGe detector, and the rotational $(\Delta \theta)$, translational $(\Delta x)$ and elevational $(\Delta z)$ step sizes to be used, which may differ for the ACT and PCT modes. The optimum data acquisition time spent at each step is determined by the ACT source strength, the waste density and the statistical accuracy required of the attenuation "maps." PCT data acquisition times will determine the minimum detectable limits and associated errors as a function of matrix density and isotope. All of the above parameters, once defined, will determine the drum throughput rate. We will use a prototype 1 -HPGe-detector A\&F CT system now being assembled at LLNL to begin to define these parameters. Parallel to this effort we will order, procure, assemble, test and optimize the 1HPGe-detector A\&P CT system to be delivered to SWEPP for demonstration, test and evaluation during INEL's planned buried waste integrated demonstration. 


\section{Readiness for Demonstration}

We are assembling a prototype 1-HPGe-detector A\&P CT system and are defining the parameters necessary to carryout an A\&P CT drum scan (see preceeding paragraph). It is not prudent to deploy this primitive prototype to SWEPP for demonstration; rather it would be better to deploy a complete, standalone A\&P CT system. This will require the procurement of one HPGe detector and its supporting electronics, a drum turntable, and computerized data acquisition and image reconstruction hardware. In the paragraphs below we state the time and funding required to procure, assemble, test and deploy such a system to SWEPP.

This 1-HPGe-detector A\&P CT system can be made operational at SWEPP by the end of FY1993. This system will be designed, procured and assembled during the remaining 9-months of FY92. It will be tested and optimized at LLNL prior to delivery to SWEPP in the first half of FY93; delivered to SWEPP in the third quarter of FY1993; and installed there during the fourth quarter of FY93. The demonstration, testing and evaluation for 55-gallon drums using this system would begin late in FY93 and be further opumized by the LLNL and SWEPP staff in early FY94.

To within a $\pm 15 \%$ contingency factor, the approximate funding required is $\$ 710 \mathrm{k}$ in FY1992, $\$ 1.050 \mathrm{k}$ in FY1993 and $\$ 140 \mathrm{k}$ in FY 1994 for a total development costs of $\$ 1.9 \mathrm{M}$. The fiscal year costs breakdown is discussed in Section IV.E below.

\section{Baseline Performance vs Projected Performance}

There are no instruments capable of measuring, identifying, localizing and accurately quantifying all radioactivites detectable in mixed-waste. Current practice in DOE for characterizing such wastes include the three NDA techniques discussed in Section II. In the next paragraph we discuss the technical basis for SGS, summarize its baseline performance and limitations, and discuss the A\&P CT scanner's potential.

\section{Current Technolgy vs. Proposed Technology}

The SGS technique was designed to measure spatially averaged passive gamma-ray intensities of either ${ }^{239} \mathrm{Pu}$ or ${ }^{235} \mathrm{U}$, only two of the 13 actinide isotopes required by WIPP's waste acceptance criteria. A typical passive measurement requires 100 seconds (s) for each 3.2-inch vertical section or segment of a revolving drum. Ten such measurements complete an assay, which requires 1000 s but measurement times can be 3000 s or longer. For the active measurement, a radiation source is used to obtain an integrated average attenuation for the drum contents by rotating the drum continuously, and data is acquired for each of the ten segments. This measurement also requires 1000s or longer; thus, 2000s to 6000s are required for a complete SGS measurement. The matrix attenuation values obtained from the transmission scans are applied to each segment's average passive gamma-ray intensity, and the segment values summed to obtain the total drum activity. Quoted precisions obtained for SGS assays of weapons grade (WG) Pu in 55-gal. drums are $\pm 100 \%$ for $\leq 1 \mathrm{~g}, \pm 10 \%$ for $10 \mathrm{~g}$, and $\pm 3 \%$ for $30 \mathrm{~g}$ [5]. The maximum allowable $239 \mathrm{Pu}$ content in a drum differs from site to site, but must be $\leq 200$ grams to meet WIPP disposal requirements. For a 55-gal. drum containing 100 net $\mathrm{kg}$ of wastes, only 160 milligrams of ${ }^{239} \mathrm{Pu}$ are required to shift the drum from the LLW to the TRU category. SGS as now practiced throughout DOE, is not capable of making an accurate assay for such a small amount of ${ }^{239} \mathrm{Pu}$.

The proposed 1-HPGe A\&P CT system will measure most detected isotopes present in the drum, which may include fission products, transuranic isotopes, and environmental radioactivities. It is designed to measure all radioactivities, not just one or two specific isotopes. The ACT measurement uses multiple monoenergetic gamma rays and a well-collimated source and detector to accurately determine the absolute attenuation functions within the drum. Since this is not a spatially averaged attenuation measurement and the active measurements are acquired close to the measured passive gamma-ray energies, more accurate corrections can be applied for either homogeneous or heterogeneous matrices, i.e., no a priori information about drum contents is required. We will also obtain well-collimated passive gamma-ray measurements that localize the radioactivity resident within the drum; and most importantly, when these data are coupled with the detailed attenuation functions from the ACT measurements, accurate and quantitative isotopic identification and specific activities are determined.

The A\&P CT measurement technology will be able to certify when mixed wastes are below the LLW threshold, meet current certification regulations for LLW, and accurately quantify TRU wastes that must be shipped to WIPP. The A\&P CT system will also be able to identify those actinide wastes that exceed WIPP limits. Preliminary results indicate we can detect amounts of ${ }^{239} \mathrm{Pu}$ below the $100 \mathrm{nCi} / \mathrm{gm}$ threshold value for LLW in a sand matrix in a 10,000 s measurement. It is important to note that the CT measurements inherently require many more measurements than SGS. Thus, using only a single-detector

$$
-6-
$$


A\&P C'T system, estimated measurment times may be from $2 x$ to $4 x$ longer than a 6000 s SGS measurement. However, our full-scale IMPACT ;stem, which will use 5-HPGe detectors, may reduce this measurement time by a factor of 5 while at the same time providing minimum detectable levels for most detected isotopes from 10 to as much as 50 times lower than those presently obtainable using SGS.

\section{Cost Savings and Cost Effectiveness}

A substantial reduction in waste disposal costs will be realized even if only a small percentage of the GAO's estimated one million 55-gallon waste drums are assayed as not TRU [2]. Our visits to INEL, ORNL and SRS revealed that $30 \%$ to $50 \%$ of their current throughput is LLW. Disposal costs for drums certified as TRU exceed $\$ 2500 /$ drum [2], while costs for drums certified as LLW amount to only $\$ 200$ to $\$ 300$ per drum. Thus, cost savings are about $\$ 2000$ per certified LLW drum; hence, 500,000 certified LLW drums will save 1 billion dollars, or $\$ 50 \mathrm{M}$ per year for the next 20 years!

Demonstration of the proposed 1-HPGe-detector A\&P CT system at SWEPP will be cost effective if it eliminates the need to open drums with unknown contents while at the same time accurately certifying the drum contents as LLW, TRU or otherwise. The full-scale system (IMPACT) will be even more cost effective since it will be more sensitive and have a higher throughput than the 1-HPGe-detector system. For example, if the total overall development cost for the A\&PCT program including replacing the 1HPGe-detector system with IMPACT is $\$ 10 \mathrm{M}$, then payback will occur after approximately 5000 drums are certified as LLW.

\section{Envisioned Performance Specifications and Limitations}

It has been demonstrated that CT improves the assay of heterogeneous waste [11-13]; therefore, it can effectively assay all classes of waste. However, we will use HPGe-detector-based systems to further improve energy resolution and assay accuracy, as well as identify most detected radioisotopes. Drum throughput through the 1-HPGe-detector system will be more than $5 \mathrm{x}$ less than that through IMPACT. The former demonstrates the proof-of-principle, the latter implements the technology. IMPACT will offer a more automated scanning capability and will require fewer hands-on drum interactions. We project about 1.5 hours will be required for an IMPACT scan, hence yield a throughput of 16 drums per day. The useful life expectancy of such a system would be from one to three decades based on our experience with many automated counting systems operating at LLNL since the late 1960's.

The 1-HGPGe-detector demonstration system will analyze 55-gallon drums, but will not be able to assay crates, half-boxes, and other odd-shaped containers. The proposed technology is not limited by the principles of computed tomography, but are governed by the fundamental principles of physics. These limitations arise from the waste form (very large crates) and/or waste type (highly attenuating waste matrix, e.g., lead). Present assay techniques, PAN, SGS, and even CT depend on the detection of radiations that originate within the wastes (passive mode) and determination of the attenuation caused by the waste matrix (active mode). CT differs from SGS and PAN in that it offers the ability to measure the attenuation of unknown heterogeneous matrices, localize any detectable radiations within the wastes, and accurately correct an internal source strength for any overlying matrix attenuations. Thus, it is a better technology to characterize wastes. The proposed CT scanner will meet current regulatory requirements and includes the flexibility to increase NDA/NDE performance in the face of future more stringent regulatory requirements. This flexibility resides in the drum scanner's components and its data acquisition and image-analysis parameters. The future viability of any scanning technology may be limited more by its ability to meet ever changing regulatory requirements than by instrument life expectancy.

\section{E. Regulatory Requirements and Public Acceptance}

There are regulatory requirements associated with the use of a radioactive source necessary to carryout active CT scans, but these safety regulations are no more restrictive than those imposed on the use of x-ray machines. At LLNL, we currently meet all OSHA and other regulations in our routine active CT scans. Such regulations protect personnel from inadvertent exposures to ionizing radiation.

We have no doubt that either the 1-HPGe- or the 5-HPGe-detector A\&P CT drum scanner systems as envisioned will be acceptable because medical and industrial CT scanners are used and accepted; and SGS scanners are now used throughout DOE and elsewhere to carryout routine drum scans. Our single detector A\&P CT scanner or the more developed, turn-key drum scanner, IMPACT, will simply be one more system that scans drums like the RTR, SGS and PAN units do now. 


\section{A. Data Requirements}

The A\&P CT drum scanner will obtain quantitative radioisotopic inventories for a range of mixedwaste densities. These data will establish the range over which it can accurately distinguish between LLW and TRU. Such data will be needed to establish the minimum detectable levels versus waste density for those fission product and transuranic isotopes that must be characterized for WIPP, transportation, and LLW land-burial requirements. These data may also define the ability of the A\&P CT drum scanner to identify nonVOCs and heavy metals within mixed wastes. Both 2-D and 3-D ACT "maps" will be obtained and these data, in concert with results from RTR and PAN, will establish the significance of helfulness that the proposed A\&P CT system will provide to the existing NDA techniques.

The operating parameters for the A\&P CT scanner need to be determined as was discussed in section III.B and III.D. Waste characteristics for 55-gallon drum interrogation will vary from minimum (plastic and paper materials $\sim 50 \mathrm{~kg} / \mathrm{drum})$ to maximum drum weights allowable $(\leq 500 \mathrm{~kg})$. The environmental conditions will be those that exist at the SWEPP facility. The A\&P CT drum scanner will require only minor modifications within the SWEPP working environment. One constraint is the necessity for a local supply of liquid nitrogen to replenish that used by the HPGe detector(s).

To establish the quality and applicability of data obtained by the proposed drum scanner, a number of sir.. dlated 55-gallon drums containing a selected range of wastes and isotopes will be assembled. With known isotopic inventories and known waste contents, these simulated drums and a study of real waste drums will help establish the operating parameters and range over which the A\&P CT drum scanner can differentiate between LLW and TRU wastes. To verify the results obtained by the drum scanner one or two real waste drums may have to be disassembled to confirm the findings of the A\&P CT drum scanner. This would require the nearby availability of hot cells and/or glove boxes.

\section{B . Operational Support Requirements}

We visited the SWEPP facility and have verified that it has sufficient space to house either a 1HPGe-detector system or the IMPACT scanner. We need at least two 30-amp circuits to support normal operation of the scanner. We also must have the supporting computer, data storage media and electronics operate in a temperature controlled environment (heated and air conditioned room). The LN need has already been mentioned. We believe SWEPP must provide operator(s) that will be trained by LLNL for the 1-HPGe-detector A\&P CT system, and technician support for periodic maintenance of the system.

\section{Regulatory Requirements}

The regulatory requirements will be minimum. As already discussed in section III.E, the drums will be interrogated using a highly collimated radioactive source; so, suitable precautions would have to be put in place to warn and protect local personnel from the effects of this ionizing radiation. We do not forsee any significant confining regulations at this time that would prevent implementation of either a 1- or 5-HPGedetector scanner system at INEL's SWEPP facility.

\section{Schedule Requirements}

Figure 7 shows in bar-chart form a proposed schedule required to implement and demonstrate a prototype 1-HPGe detector A\&P CT drum scanner at the INEL/SWEPP facility.

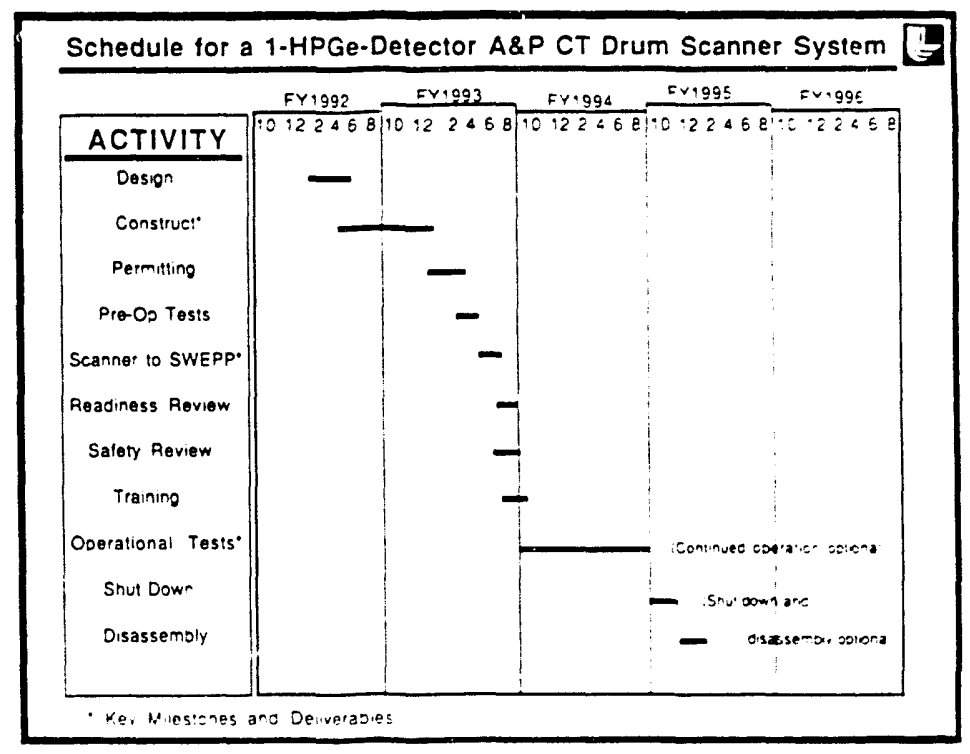

Fig. 7. A proposed schedule in bar-chart form for deployment of a 1-HPGe detector A\&P CT drum scanner system to INEL's SW'EPP facility. The key milestones and deliverables are shown by asterisks. 


\section{E. Funding Requirements}

\section{Requirements for a 1-HPGe-detector A\&P CT Scanner System}

Table I outlines the cost per fiscal year required to implement the proposed 1-HPGe-detector, A\&P CT drum scanner system at the INEL SWEPP facility. The stated costs are only accurate to about $\pm 15 \%$.

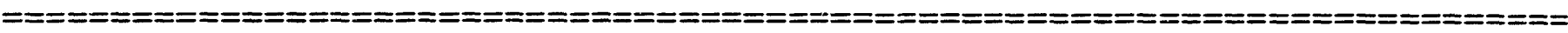

TABLE I. PROJECTED COSTS (k\$) FOR A 1-HPGe DETECTOR A\&P CT SCANNER AT SWEPP*

\begin{tabular}{|c|c|c|c|c|c|c|c|}
\hline $\begin{array}{l}\text { Fiscal } \\
\text { Year } \\
\end{array}$ & \multicolumn{2}{|c|}{$\begin{array}{l}\text { Man- } \\
\text { power } \div\end{array}$} & $\begin{array}{l}\text { Cap. } \\
\text { Eqpt }+\div\end{array}$ & $\begin{array}{l}\text { Other } \\
\text { Mat'ls } † \dagger+\end{array}$ & $\begin{array}{l}\text { Site } \\
\text { Prep. } \$\end{array}$ & $\begin{array}{l}\text { Util- } \\
\text { ities } \$ \S\end{array}$ & $\begin{array}{l}\text { TOTAL } \\
\text { COSTS** }\end{array}$ \\
\hline FY1992 & \multicolumn{2}{|l|}{300} & & 60 & - & - & 710 \\
\hline FY'1993 & \multicolumn{2}{|l|}{600} & - & 250 & 195 & 5 & 1,050 \\
\hline FY1994 & \multicolumn{2}{|l|}{$120 *$} & - & 20 & - & $-* *$ & 140 \\
\hline \multicolumn{3}{|c|}{ Manpower: } & & & & & \\
\hline \multirow{2}{*}{\multicolumn{2}{|c|}{$\begin{array}{l}\because \quad \text { Capital Eqpt: } \\
\div \div \text { Other Materials: }\end{array}$}} & & & & & & \\
\hline \multirow{2}{*}{\multicolumn{2}{|c|}{$\begin{array}{l}\text { Other Materials: } \\
\text { Site Prep: }\end{array}$}} & \multicolumn{6}{|c|}{$\mathrm{HPGe}(\mathrm{s}) ; \mathrm{Pb}$-stainless steel shield; A CT radiation source; supplies and expenses. } \\
\hline & & \\
\hline & $\begin{array}{l}\text { Site Prep: } \\
\text { Utilities: }\end{array}$ & \multicolumn{6}{|c|}{$\begin{array}{l}\text { Projected costs for SWEPP to prepare for A\&P CT scanner demonstration. } \\
\text { Projected electrical and LN supply costs. }\end{array}$} \\
\hline
\end{tabular}

\section{Requirements for IMPACT, a 5-HPGe-detector Scanner System}

We believe that it is essential to begin planning implementation of a 5-HPGedetector scanner system even as the effort begins to deploy our 1-HPGedetector system. A preliminary and brief schedule for the deployment of IMPACT to SWEPP is seen in Fig 8.

The program to develop a 5 HPGe-detector scanner system must begin in parallel with the effort that develops the 1-HPGe detector system, because the former is significantly more complex and ambitious in its construction requirements. We would begin a two and a-half year R\&D program (thru FY94) that develops a 5-detector A\&PCT drum scanner system in FY1993. We would optimize the performance of this prototype in FY1994, during the last year of the R\&D effort, but concurrently begin the first year of a two-year demonstration, test and evaluation (DT\&E) program. During year one of the DT\&E (FY1994) we purchase all required components and develop a more turnkey scanner, IMPACT, which would be installed at SWEPP during FY1995 with initial operational training provided during the final quarter of FY1995. Note that installation occurs shortly after the 1-IPGe system has been tested at SWEPP for about one year. LLNL would train SWEPP personnel to operate IMPACT and join the SWEPP staff in optimizing IMPACT's performance.

The funding required for this option is: $\$ 900 \mathrm{k}$ in FY1992; $\$ 1,200 \mathrm{k}$ in FY1993; $\$ 1,800$ in FY1994; $\$ 1,500$ in FY1995; and $\$ 400 \mathrm{k}$ in FY 1996; a 5 -year effort for $\$ 5.8 \mathrm{M}$. The costs breakdown is:

FY1992 $=\$ 500 \mathrm{k}$ in FTE costs $+\$ 400$ in expense costs (5 HPGe detectors; a Sun computer system).

FY1993 = \$800k in FTE costs $+\$ 400$ in expense costs (a motorized drum platform; an active source; and cuntrol hardware).

FY1994 $=\$ 800 \mathrm{k}$ in FTE costs $+\$ 1,000 \mathrm{k}$ expense costs $(5 \mathrm{HPGe}$ detectors; a motorized drum platform; a Sun computer system; $\$ 60 \mathrm{k}$ for active source; and a $\mathrm{Pb}$ shield design/fabrication).

FY $1995=\$ 600 \mathrm{k}$ in FTE costs $+\$ 900 \mathrm{k}$ in expense costs (SWEPP prep costs; delivery and installation).

FY1996 $=\$ 400 \mathrm{k}$ in FTE costs. 
The proposed A\&P CT technology and other promising technologies [14-17] are needed by all DOE sites that generate wastes containing radioactivity. These sites must certify that their wastes are either low level (LLW) or transuranic (TRU). Each category of wastes must meet different disposal, burial and transportation (DoT) regulations, while TRU wastes must also meet WIPP's waste acceptance criteria. The proposed A\&P CT scanner will be able to assay quantitatively and accurately the amount of LLW and/or TRU isotopic content in 30- to 96-gallon waste drums without prior knowledge of drum contents. In addition, the A\&P CT drum scanner may offer the possibility of identifying the presence of nonvolatile organic compounds and heavy metals without opening the drum. Clearly, it has broad applicability across the DOE complex and once successfully demonstrated can be commercially developed, marketed and installed at all DOE sites.

IMPACT is a better waste assay technology relative to SGS because more and larger HPGe detectors are used, and the proposed A\&P CT drum scanner offers minimum detection limits 10 to 50 times lower than those obtained by the SGS technique. Detection limits for most of the radioactivities detected, not just the TRU isotopes, will be lower. Furthermore, most detected activities will be identified and their assay errors may be up to ten times lower than those for SGS. In addition, ricsults from the A\&P CT drum scanner might be used to improve the PAN assay correction values for drum matrix heterogeneity. Finally, this new technology offers an excellent probability of identifying the presence of nonVOCs and heavy metals nondestructively, i.e., without opening the waste container.

It is a cheaper way of assaying containerized wastes. If it delivers all that is promised, then fewer drums will have to be opened to verify their contents. It will also save disposal costs when the cost of full-scale IMPACT units are amortized over the many years to be spent in shipping drums to WIPP because fewer drums will be declared TRU. Once DOE's decontamination and decommissioning (D\&D) program is fully implemented, IMPACT will also certify those D\&D wastes that are indeed LLW and clearly differentiate them from those wastes that are TRU. Hence, LLW D\&D wastes will be disposed of at significantly reduced costs.

Once passive CT technology matures, and certainly if envisioned 3-D or cone-beam CT imaging becomes practical, future A\&P CT drum scanners will offer even faster drum scan times than those currently being used for SGS assays, and it will offer considerably improved accuracy.

The proposed A\&P CT drum scanner technology will be safer because it will accurataly identify drum contents; and perhaps all material attenuations and effective atomic numbers, whether radroactive or not, can be quantified. Such information eliminates the need for invasive inspections of drums with either known or unknown contents. Clearly, if fewer drums must be opened, then both exposure dose and risks to drum inspection personnel are reduced. Automation of routine drum scannirig in the SWEPP facility will further reduce personnel exposures. So, the A\&P CT technology helps DOE meet the as low as reasonably achievable (ALARA) objective in waste assay certification handling. Finally, the non-DOE public will benefit from this new technology once commercial versions of IMPACT are marketed and deployed for use by hospitals, reactors, state agencies, regulatory agencies and low level disposal sites.

\section{ACKNOWLEDGEMENTS}

We appreciate the assistance provided by Dan Schneberk, Pat Roberson, Zach Koenig, Tom Barlow, Satish Kulkarni, and Dan Decman who v ere kind enough to read near final drafts of this report and make helpful suggestions.

This work was performed under the auspices of the U. S. Department of Energy by the Lawrence Livermore National Laboratory under Contract W-7405-Eng-48, and support for this report was provided by the Idaho National Engineering Laboratory's Buried Waste Integration Demonstration funding. 


\section{REFERENCES}

1. "Nondestructive Examination and Assay System. Research and Development Requirements to Meet Evolving Regulations," Draft Report by D. J. Osetek and B. C. Anderson, (Private Comunication), 1991.

2. "NUCLEAR WASTE: Storage Issues at DOE's Waste Isolation Pilot Plant inNew Mexico," Government Accounting Office Report GAO/RCED-90-1 (1990).

3. Preliminary Draft Report, "Decontamination and Decomissioning Integrated Demonstration Strategy," by a Workshop Pänel selected by DOE/OTD, Chairman Johnny Moore, DOE-ORO, (Private Communication), October 1991.

4. Tom Clements and Tim Roney, Idaho National Engineering Laboratory (Private communication), 1991.

5. "DOE Assay Methods Used for Characterization of Contact-Handled Transuranic Waste," F. J. Schultz and J. T. Caldwell, Oak Ridge National Laboratory Report, ORNL-6485, 1991.

6. "Nondestructive Assay of Plutonium Bearing Scrap and Wastes with the Advanced Segmented Gamma-Ray Scanner," S. M. Simmonds, et al., Lus Alamos National Laboratory, Repcrt LA-UR-90-2253, 1990; and TRU-ART: A Cost-Effective Prototypical Neutron Imaging Technique for Transuranic Waste Certification Sytems," W. S. Horton, Los Alamos National Laboratory, Ph.D. Thesis LA-11523-T, 1988.

7. "Computerized Tomography," H. E. Martz, et al., in Energy and Technology Review, Lawrence Livermore National Laboratory Report, UCRL-52000-90-11·12, 1990.

8. "Isotopic Assays of Nuclear Wastes Using Tomographic Techniques", D. C. Camp, H. E. Martz, Z. M. Koenig, and S. C. Azevedo, Trans. Am. Nuc. Soc., ANS Vol. 63, p 66, June 1991.

9. "Nuclear Spectroscopy-Based, First Generation, Computerized Tomography Scanners," H. E. Martz, et al., IEEE Transactions on Nuclear Science, 38, \#2, May, 1991.

10. "Considerations for an Active and Passive Scanner to Assay Nuclear Wastes Drums," H. E. Martz, S. G. Azevedo, G. P. Roberson, D. J. Schneberk, Z. M. Koenig, and D. C. Camp, ASNT's Industrial Computed Tomography II Topical Conference, San Diego, CA, May 20-24, 1991, pp. 143-147, 1991.

11. "Non-Destructive Waste Form and Package Characterization by Computerized Tomography," B. Illerhaus, J. Goebbels, A. Keitschau and P Reimers, Mat. Res. Soc. Symp. Proc., Vo. 127, pp. 507-512, 1989.

12. "Radioactivity Measurement of Drum Package Waste by a Computed-Tomography Technique," S. Kawasaki, M. Kondo, S. Izumi and M. Kikichi, Appl. Radiat. Isot. Vol. 41, pp. 983-987, 1990.

13. "Assay of Heterogeneous Radioactive Wastes by Low-Resolution Tomographic Gamma Scanning," R. J. Estep, Los Alamos National Laboratory Report, LA-UR-90-2054, 1990.

14. "Associated Particle Imaging System." Special Technologies Laboratory, EG\&G Energy Measurements, Santa Barbara, CA, Report STL-5000-0004, July 1991.

15. "Nuclear Waste Drum Assayer," R. L. Brtodzinski and P. J. Turner, in Waste Management '90, p. 235-237, 1990.

i6. "The APNEA Unit, The Next Gerneration Device for the Nondestruictive Assay Study of Transuranic Waste," D. C. Hensley, et al. Oak Ridge National Laboratory, Transuranic and Hazardous Waste Characterization Information Exchange, Pocatello Idaho, July 16, 1991.

17. "Gamma-Ray Assay of a Waste Drum for the Determination of Plutonium Amount," J. Akatsu, T. Kimura and H. Mutoh, Journal Nuclear Materials Management, Vol. 18, pp. 21-25, 1990. 

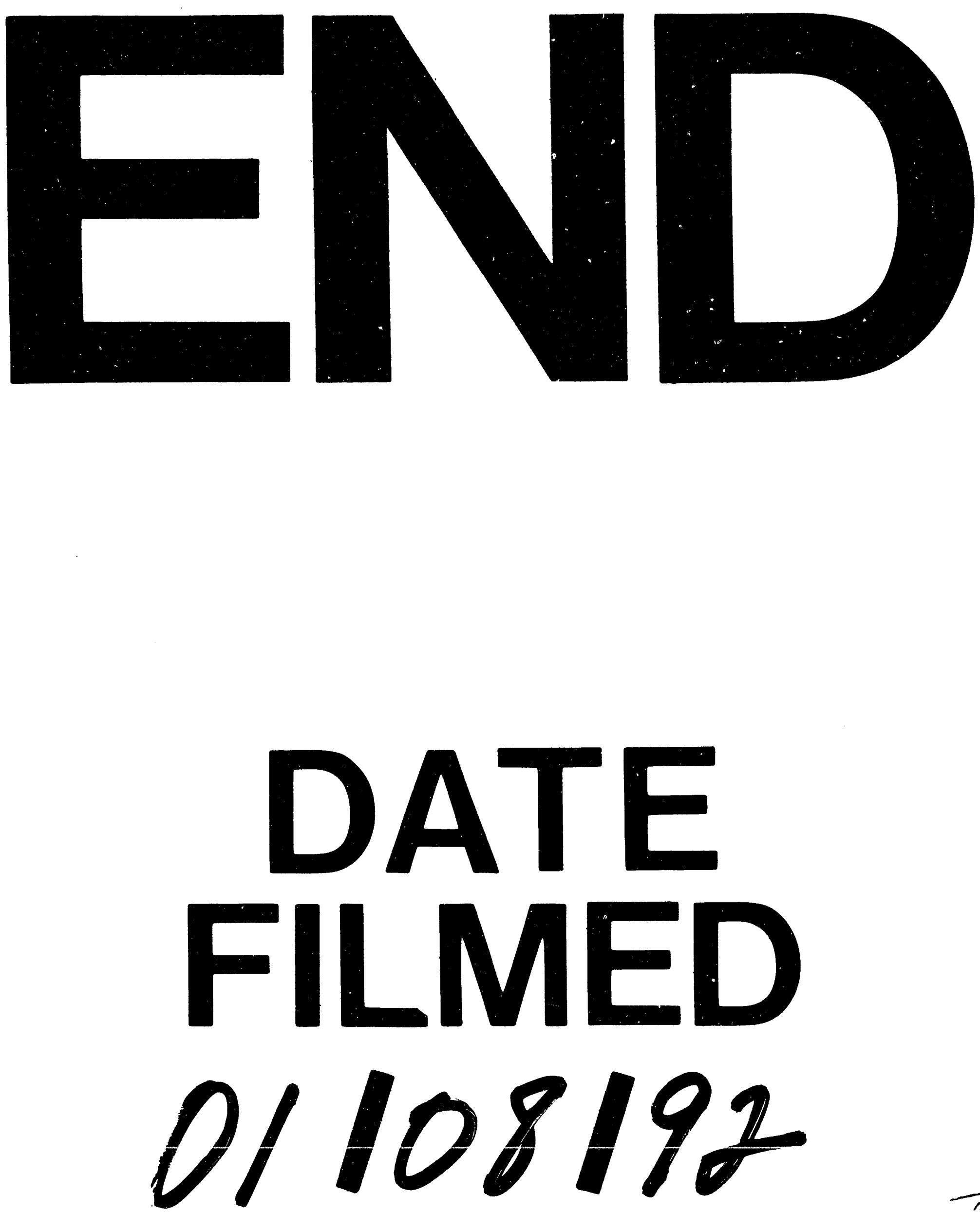
